\title{
Hyperkalemia in heart failure patients: current challenges and future prospects
}

This article was published in the following Dove Press journal:

Research Reports in Clinical Cardiology

9 February 2016

Number of times this article has been viewed

\author{
Raquel López-Vilella \\ Herminio Morillas-Climent \\ Diego Plaza-López \\ Mónica Cebrián-Pinar \\ Ignacio Sánchez-Lázaro \\ Luis Almenar-Bonet \\ Heart Failure and Heart Transplant \\ Unit, Cardiology Department, \\ Hospital La Fe, Valencia, Spain
}

\begin{abstract}
In heart failure (HF), hyperkalemia is a frequent problem because of several factors, such as neurohormonal mechanisms involved in the disease, renal failure, comorbidities, and drugs with a prognostic benefit. These drugs can block the renin-angiotensin-aldosterone system, and therefore, serum potassium levels can increase, mostly when combined with other drugs as nonsteroidal anti-inflammatories, digitalis, heparin, etc. Hyperkalemia can have severe consequences if not corrected, mostly at the cardiac level (decrease in speed conduction, QRS enlargement, ventricular arrhythmias, and asystole). Therefore, it is important to adequately prescribe these potentially harmful drugs (starting at low doses with close monitoring of renal function and potassium levels), to carefully manage the factors that can interfere with potassium levels, and to early treat hyperkalemia if it develops. There are several investigation lines for the design of new molecules that show a similar efficacy to that of renin-angiotensin-aldosterone system, with a lower risk of hyperkalemia: nonsteroidal mineralocorticoid receptor antagonists like finerenone, which is a more cardioselective drug than traditional mineralocorticoid receptor antagonists, and angiotensin and neprilysin inhibitors such as LCZ696, which have proven to reduce mortality and heart failure hospitalizations. Besides, new drugs are being studied, which are able to reduce levels of serum potassium in a sustained and faster way, like chelating polymers Patiromer and sodium zirconium cyclosilicate.
\end{abstract}

Keywords: hyperkalemia, heart failure, renin-angiotensin-aldosterone system inhibitors

\section{Introduction and objectives}

In heart failure (HF), potassium balance is affected by neurohormonal mechanisms involved in the disease, as well as by those drugs used for its treatment. ${ }^{1}$ In HF, a significant reduction in morbidity and mortality is related to neurohormonal activation inhibition by multiple levels of angiotensin-converting enzyme (ACE) inhibitors, angiotensin II receptor blockers (ARBs), mineralocorticoid receptor antagonists (MRAs), and renin inhibitors. ${ }^{2,3}$ Nevertheless, these treatments can increase serum potassium levels. Hyperkalemia caused by these agents is not frequent in patients who lack other predisposing factors. However, patients with HF frequently show comorbidities and a certain degree of renal failure, a factor known as an independent death predictor in patients with $\mathrm{HF}^{4}$ Therefore, the risk of severe hyperkalemia during the treatment is significant. ${ }^{5}$ In this way, patients who benefit more from the use of renin-angiotensin system blockers are those at higher risk of developing hyperkalemia.

The objective of this review is to update the knowledge about hyperkalemia in HF, its incidence and treatment, and the mechanisms through which it is produced, and to review future prevention options and therapeutic approaches.
Correspondence: Raquel López-Vilella Hospital La Fe, No 106, Fernando Abril Martorell Av, 46026 Valencia, Spain

Tel +34615884883

Email lopez_raqvil@gva.es
Research Reports in Clinical Cardiology 2016:7 I-8

submit your manuscript | www.dovepress.con

Dovepress

http://dx.doi.org/10.2147/RRCC.\$75680

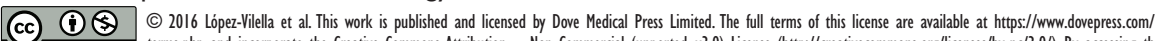
BY NC terms.php and incorporate the Creative Commons Atrribution - Non Commercial (unported, v3.0) License (http://creativecommons.org/licenses/lby-nc/3.0). By accessing the work you hereby accept the Terms. Non-commercial uses of the work are permitted without any further permission from Dove Medical Press Limited, provided the work is properly attributed. For permission for commercial use of this work, please see paragraphs 4.2 and 5 of our Terms (https://www.dovepress.com/terms.php). 


\section{Prevalence of hyperkalemia in HF}

The upper limit reference of serum potassium remains not completely clear. Although there is some evidence about an increased risk of death in patients with diabetes mellitus or chronic kidney disease (CKD) and a serum potassium $>5.0 \mathrm{mEq} / \mathrm{L}$, we decided to consider normal values of serum potassium until $5.5 \mathrm{mEq} / \mathrm{L}$ because data are conflicting and the majority of articles show an increase of mortality risk for potassium levels $>5.5 \mathrm{mEq} / \mathrm{L}$ but not below. In addition, $5.5 \mathrm{mEq} / \mathrm{L}$ is the reference worldwide accepted in laboratories, clinical trials, and real practice. ${ }^{6-8}$

The incidence and prevalence of hyperkalemia, defined as potassium levels $>5.5 \mathrm{mEq} / \mathrm{L}$, vary depending on the patient characteristics. Its real prevalence is unknown, although an estimated prevalence in general population is among $2 \%-3 \%$, and among $1 \%-10 \%$ in hospitalized patients. Nevertheless, hyperkalemia frequency can increase up to $40 \%-50 \%$ in patients with chronic renal failure. ${ }^{9}$ Patients with HF are especially susceptible to hyperkalemia due to advanced age and comorbidities (which entail alterations in normal potassium excretion), and also to the fact that the optimal medical treatment involves the use of renin-angiotensinaldosterone system (RAAS) antagonists, which increase the risk of hyperkalemia, especially when combined. Currently, available data reveal that hyperkalemia due to RAAS antagonists is more frequent than initially estimated. Among outpatients, up to $10 \%$ show hyperkalemia during the first year of treatment with ACE inhibitors or ARBs, ${ }^{10}$ while in hospitalized patient series, these drugs are responsible for $63 \%$ of hyperkalemia cases. Furthermore, between $10 \%$ and $38 \%$ of hospital admissions for hyperkalemia are due to the administration of these drugs. ${ }^{11}$ The risk of hyperkalemia in patients receiving RAAS blockers is $\sim 3.3 \%$, although there is an important variability in the risk because it is increased as other risk factors appear, as well as when combined with other drugs. ${ }^{12,13}$

\section{Hyperkalemia causes - potassium homeostasis}

Potassium is the most abundant cation in the human body, and is distributed mainly in the intracellular space. Almost 98\% of potassium $(\sim 140 \mathrm{mmol} / \mathrm{L})$ is found inside the cells, while only $2 \%$ of it $(3.8-5.0 \mathrm{mmol} / \mathrm{L})$ is found in the extracellular liquid. Serum potassium levels depend on the dietary intake and the renal excretion of potassium. Most of the potassium that is filtered into the glomerulus is reabsorbed in the proximal tubule $(65 \%)$ and in the loop of Henle (20\%), but the following secretion of the distal nephron, regulated by the
RAAS, is the main determinant of potassium concentration in plasma. ${ }^{14} \mathrm{An}$ increase in potassium plasma levels stimulates the liberation of renin from juxtaglomerular cells and activates the RAAS, and the aldosterone acts on the distal tubule, increasing the excretion of it. Hyperkalemia can be produced by three mechanisms: increase of potassium intake, alteration in the distribution between the extracellular and intracellular space, and decreased renal excretion. In patients with HF, due to the disease physiopathology and treatment effects, both hyper- and hypokalemia can occur, and both situations can carry severe consequences if they are not detected and corrected. ${ }^{15-17}$ Hypokalemia is more common in initial stages of HF, when the renal function is still preserved. Intensive diuretic therapy can produce significant hypokalemia, so potassium supplements are often prescribed. However, renal function worsening and a decrease in renal potassium excretion are common in advanced stages of the disease, therefore increasing the risk of hyperkalemia (especially if the patient continues with a high intake of potassium). ${ }^{18}$ Physiopathology of hyperkalemia in HF is typically multifactorial because of alterations in the transcellular distribution of potassium, and alterations in external balance when potassium renal clearance is reduced. This reduction occurs because renal excretion of potassium is decreased in HF for two reasons: a reduction in the glomerular filtration rate (that can occur even with a normal value of serum creatinine) and the pharmacologic treatment of HF, including ACE inhibitors, ARBs, and MRAs. ${ }^{19-21}$ The risk of relevant hyperkalemia in patients receiving these drugs is low if renal function is in a relatively normal interval, $\sim 3.3 \% .{ }^{22-24}$ Nevertheless, this risk increases up to $10 \%$ as risk factors appear (eg, renal chronic disease or diabetes), as well as due to the combination with other drugs (nonsteroidal anti-inflammatory drugs [NSAIDs], digitalis, heparin, cyclosporine, etc). ${ }^{25-28}$ Considering age, comorbidity, and usual polypharmacy of HF patients, the current situation is that hyperkalemia in these patients is a frequent and potentially severe problem, taking into account that indications for the use of these drugs are becoming wider. ${ }^{29}$

\section{Symptoms and hyperkalemia diagnosis}

Consequences of hyperkalemia occur due to the situation of partial depolarization that the cell membrane acquires. When this situation is prolonged, the cell membrane excitation decreases. Metabolic acidosis is also produced because hyperkalemia interferes with renal ammoniagenesis and with ammonium reabsorption in the thick portion of the 
ascendant branch of the loop of Henle, complicating the final elimination of acid. Acidosis can worsen hyperkalemia because of potassium release into the extracellular space. The worst consequences occur when potassium plasma levels exceed $7 \mathrm{mEq} / \mathrm{L}$, when hyperkalemia is chronic, or when low levels increase quickly.

Clinical presentation of hyperkalemia can sometimes be "confusing" in HF patients because it is usually asymptomatic, but the most relevant clinical expressions frequently simulate and sometimes are indistinguishable from those of HF. These are muscle weakness, cardiac conduction alterations, arrhythmias of varying severity, and even sudden death. Muscle symptoms can simulate Guillain-Barré Syndrome because muscle weakness is typically of ascendant type, with weakness of respiratory muscles being rare, thus respecting the function of cranial nerves and sphincter tone. ${ }^{30-32}$ Nevertheless, the most severe consequences are produced at the cardiac level. Hyperkalemia can produce electrocardiographic alterations with lower levels of potassium, that are asymptomatic and that may suggest the diagnoses when present. Severity and progression of these electrocardiographic alterations do not show a correlation with plasma potassium concentrations, ${ }^{33-38}$ and some of them are highly unspecific, so they are not suitable to monitor potassium levels. The earliest alteration is usually $\mathrm{T}$ wave tenting (narrowing and peaking) along with a shortening of QT interval, which explain a lower duration of action potential. Sodium channel inactivation caused by a reduction in the resting membrane potential leads to a drop in conduction speed, and produces a progressive widening of $\mathrm{P}$ wave. The $\mathrm{P}$ wave can even disappear, and this fact can be related to escape rhythms in the atrioventricular (AV) union and even lower in the ventricular conduction system. However, even if there are no visible $P$ waves, the exact nature of the rhythm cannot be established. This rhythm can be atrial rhythm and even sinus rhythm because the sinus node activity can persist, traveling to the AV node through the intraauricular conduction-specific system even if there is atrial asystole (because atrial myocardial work is more sensitive to hyperkalemia). This is known as "sinoventricular rhythm". The PR interval can be enlarged together with an advanced AV block, and the QRS complex can be widened along with a multitude of alterations in intraventricular conduction (left branch block, right branch block, bifascicular block, etc).$^{39}$ If hyperkalemia intensifies, this can lead to ventricular tachycardia, ventricular fibrillation, and asystole, typically preceded by sinusoidal rhythm. This rhythm corresponds to monophasic waves formed by the fusion of the wide QRS complex with the $\mathrm{T}$ wave, which simulate a ventricular flutter. ${ }^{40}$
Moderate or severe elevations of potassium concentration can lead to an increase of the ST segment in left precordial derivations. These derivations can simulate an ischemic pattern, and can even produce a type I Brugada pattern when it accompanies a complete left branch block. A complete left branch block can differentiate from the genetic Brugada because of the absence of $\mathrm{P}$ waves and the marked and progressive widening of the QRS complex. ${ }^{41}$

\section{Treatment of hyperkalemia in HF Suitable dosage of potentially harmful drugs}

Clinically relevant hyperkalemia incidence (serum potassium $>6.0 \mathrm{mEq} / \mathrm{L})$ is minimal $(\sim 2 \%)$ when only one RAAS inhibitor is prescribed, although serum potassium levels $>5.5 \mathrm{mEq} / \mathrm{L}$ are relatively frequent (between $7 \%$ and $10 \%$ in some studies). ${ }^{42}$ Many clinical trials have proven that dual RAAS blockade (ACE inhibitors and ARBs) does not provide benefits in chronic HF prognosis, while it produces a considerable increase of adverse events, mainly hyperkalemia. ${ }^{43}$ For this reason, this combination should be avoided. Regular treatment consists of the combination of an RAAS inhibitor (ACE inhibitor or ARB) with an MRA (spironolactone or eplerenone). As mentioned earlier, MRAs, in combination with RAAS inhibitors, provide a wide evidence of hospital admissions and mortality decrease, both in $\mathrm{HF}$ and myocardial infarction. Nevertheless, in both contexts, these drugs are underused, mainly due to a fear of the onset of one of the most frequent side effects, hyperkalemia. ${ }^{44,45} \mathrm{It}$ should be stressed that the incidence of severe hyperkalemia, meaning potassium $>6 \mathrm{mEq} / \mathrm{L}$, has fluctuated between $2 \%$ and $5.5 \%$ in big randomized clinical trials. ${ }^{46-48}$ This can be mainly due to the existence of strict inclusion and exclusion criteria (not allowing the inclusion of patients with creatinine $>2.5 \mathrm{mg} / \mathrm{dL}$ or potassium $>5 \mathrm{mEq} / \mathrm{L}$ ). Average elevation in potassium levels fluctuated between 0.2 and $0.3 \mathrm{mEq} / \mathrm{L}$ with regard to placebo, and there was no increase in hospitalizations, mortality, or treatment withdrawal because of this reason. ${ }^{49}$ Nonetheless, after publication of the RALES study, both a mild and a severe (even fatal) hyperkalemia incidence were observed in daily practice. This was attributed to a lower control in the initial dose and in the frequency of potassium levels monitoring, and later dosage adjustment. ${ }^{50}$

In consequence, the first measures to adopt in order to avoid hyperkalemia onset in HF patients are the following: i) the proper selection of the patient (having special precaution in those patients with renal failure or slightly elevated potassium); 
ii) starting therapy with a low dose (25 $\mathrm{mg}$ of eplerenone or spironolactone a day, or even every 48 hours if glomerular filtration rate [GFR] is $<50 \mathrm{~mL} / \mathrm{min} / 1.73 \mathrm{~m}^{2}$ ); and iii) close monitoring of renal function and potassium levels (72 hours after any relevant change that can affect potassium levels, and systematically at 4 weeks and every 3-4 months, while treatment with aldosterone antagonists is maintained). ${ }^{51}$

\section{Thorough management of circumstances that may interfere with potassium levels}

As mentioned earlier, due to the risk of developing hypokalemia, patients with HF usually take potassiumenriched salts or diets with high content of potassium. After the introduction of drugs that may affect potassium levels, the patient's diet should be reevaluated, avoiding to the extent possible the intake of potassium-rich food (Table 1). ${ }^{52}$ Serum potassium level $<3.5 \mathrm{mEq} / \mathrm{L}$ has also been related to a higher mortality, and it should be highlighted that taking aldosterone antagonists reduces substantially its onset. ${ }^{53,54}$

Potassium displacement from the intracellular to the extracellular environment does not involve a big problem. However, in hyperkalemia settings, digoxin dosage should be reviewed in order to avoid potassium accumulation, low doses of cardioselective beta-blockers should be prescribed, and acidosis situations should be corrected. ${ }^{55-57}$

Potassium levels must always be monitored after the introduction of drugs that may affect potassium homeostasis, some of which are widely used in HF: NSAIDs, high doses of loop diuretics (if they produce hypovolemia), heparin, cotrimoxazole, calcineurin inhibitors, Tolvaptan, etc. ${ }^{58}$ Because eplerenone is metabolized by the cytochrome p450 isoenzyme 3A4, concomitant use of drugs with a strong inhibition of such enzymatic system (ketoconazole, fluconazole, erythromycin, verapamil) may increase potassium blood levels, and therefore, the risk of hyperkalemia. Such situation does not occur with spironolactone because it is metabolized by the liver but is not subtracted by CYP3A4. For this reason, it should be considered as the mineralocorticoid antagonist of choice when enzymatic inhibitors in high or prolonged doses

Table I Potassium-rich food

\begin{tabular}{lll}
\hline Fruits & Vegetables & Other \\
\hline Avocado & Beans & Chocolate \\
Banana & Carrot & Milk \\
Grapefruit & Potato & Walnuts \\
Orange & Tomato & Peanut butter \\
Apricot & Pumpkin & Yogurt \\
Raisins & Spinach & Bran \\
\hline
\end{tabular}

are used. Finally, it is essential to train the patients who take potassium-sparing drugs about concomitant pathologies that may alter potassium homeostasis, as diarrhea and vomiting. If these symptoms show up, patients should visit their medical practitioner to monitor potassium levels and even suspend the medication if fluid loss is intense.

\section{Acute and long-term treatment of hyperkalemia}

Hyperkalemia needs to be managed both in the short and long term, and there are plenty of measures and drugs for this purpose (Table 2). In the acute phase, the priority in the quick establishment of hyperkalemia treatment should be marked by the presence of electrocardiographic alterations. Electrocardiogram (EKG) is not a reliable guide to the level of serum $\mathrm{K}^{+}$, and the existence of hyperkalemia without any EKG change is relatively frequent, especially in advanced $\mathrm{CKD}$ patients. However, it is logical to suppose that the risk of developing potentially lethal arrhythmias increases as baseline EKG alterations appear, although there are no clinical trials available about this topic (there is only little evidence suggesting that $T$ wave tenting is associated with sudden cardiac death). ${ }^{59}$ Indeed, several authorities ${ }^{30,36,52}$ recommend treatment for hyperkalemia when EKG changes are present or when serum potassium levels are $>6.0-6.5 \mathrm{mEq} / \mathrm{L}$.

In case EKG changes exist, calcium gluconate should be injected immediately. This drug acts antagonizing potassium effects over the myocyte cell membrane immediately, without affecting potassium concentrations in plasma. It is important to have in mind that the half-life of calcium gluconate is 60 minutes, so a new dose should be provided if, after this time, potassium levels are still high ${ }^{60}$ Concomitantly, insulin administration should begin ( 10 IU of regular insulin diluted with $50 \mathrm{mg}$ pure dextrose to avoid hypoglycemia) because this is the most effective and safe treatment to reduce potassium

Table 2 Hyperkalemia short- and long-term treatment

\begin{tabular}{|c|c|c|}
\hline Therapy & Start & Mechanism \\
\hline Calcium gluconate & Fast & $\begin{array}{l}\text { Antagonize excitation } \\
\text { of membrane }\end{array}$ \\
\hline Insulin and dextrose & Intermediate & Moves potassium inside the cell \\
\hline $\begin{array}{l}\text { Beta-adrenergic } \\
\text { antagonists }\end{array}$ & Intermediate & Moves potassium inside the cell \\
\hline Sodium bicarbonate & Intermediate & Moves potassium inside the cell \\
\hline Diuretics & Late & $\begin{array}{l}\text { Increases potassium urine } \\
\text { excretion }\end{array}$ \\
\hline Resins & Late & $\begin{array}{l}\text { Increases potassium } \\
\text { gastrointestinal excretion }\end{array}$ \\
\hline Dialysis & Late & $\begin{array}{l}\text { Potassium extracorporeal } \\
\text { elimination }\end{array}$ \\
\hline
\end{tabular}


levels in HF patients. The mechanism of action of insulin is based on the stimulation of the $\mathrm{Na}^{+}-\mathrm{K}^{+}$-ATPase pump, and therefore, in the introduction of potassium from the extracellular to the intracellular environment. Administering $10 \mathrm{IU}$ of insulin can decrease the levels of potassium between 0.5 and $1.5 \mathrm{mEq} / \mathrm{L}$, and its effect lasts $\sim 4-6$ hours. ${ }^{61,62}$ Betaadrenergic antagonists and sodium bicarbonate effectiveness and start time are similar to those of insulin. However, both drugs are considered of second choice in HF hyperkalemia treatment because of their potential side effects, such as tachycardization with beta-adrenergic antagonists and sodium overload with bicarbonate. ${ }^{63,64}$ When these measures are not effective, dialysis should be used, considering this option the last resource due to its lower speed to reduce potassium levels to normal limits. Numerous studies suggest that hemodialysis is more effective than peritoneal dialysis to eliminate potassium excess.

At the same time that fast-acting therapy to introduce potassium inside the cells is started, long-duration treatment to eliminate potassium overload should begin. Diuretics are the drugs of choice because of their good tolerance and efficacy over urinary potassium elimination. In patients with preserved renal function, thiazide diuretics are preferred, while in patients with a GFR $<30-40 \mathrm{~mL} / \mathrm{min}$, due to the reduction in thiazide action, loop diuretics are usually used. ${ }^{65}$ An adequate management of volemia is basic, avoiding excessive dehydration, because even if an increase of the urine flow facilitates potassium excretion, an excessive elimination of liquid can lead to renal failure of pre-renal origin, and in consequence, to hyperkalemia worsening. ${ }^{66}$

On the other side, ion-exchange resins can help maintain potassium levels within normality limits. Their main problem lies in their mechanism of action, that is based on potassium elimination in exchange of sodium retention at gastrointestinal level, creating a potential sodium retention at intravascular level with potential deleterious effects over HF. Besides, a frequent side effect is constipation onset or aggravation, so ion-exchange resins should be prescribed together with a laxative during the first weeks. The usual dose of ion-exchange resins for hyperkalemia prevention consists of one or two weekly single doses of $30-45$ g. ${ }^{67}$

\section{New perspectives in prevention and treatment of hyperkalemia in HF}

Despite all the measures mentioned earlier, and mainly in those patients with a certain deterioration of their basal renal function, sometimes the prescription of aldosterone antagonists is impeded by a trend toward hyperkalemia. Due to the noticeable prognostic benefit of these drugs, investigation lines over the past years have focused on the design of new molecules with a similar effect, but less interaction with potassium levels, and on obtaining potassium binders that allow aldosterone antagonists to be administered with minimal risk.

In preclinic models, new nonsteroidal MRAs have proven to associate with a lower risk of hyperkalemia compared with placebo, reducing microalbuminuria in patients with diabetic nephropathy, without worsening renal function or hyperkalemia. Finerenone is a nonsteroidal aldosterone antagonist that has affinity for mineralocorticoid receptors, similar to that of spironolactone, and a specificity similar to that of eplerenone. Unlike finerenone, spironolactone, and eplerenone, in which biodistribution in the kidney is much higher than in the heart, in the case of finerenone, the distribution is comparable (it is more cardioselective). This fact was considered as one of the main hypotheses that could explain the lower incidence of hyperkalemia. In a recent Phase II study, every different dose of finerenone provoked a smaller increment in serum potassium levels than spironolactone $50 \mathrm{mg}$ daily at 30 days $(0.04-0.30$ versus $0.45 \mathrm{mmol} / \mathrm{L})$. In addition, finerenone decrease of GFR was slightly lower than spironolactone $(0.38-3.0$ versus $5.73 \mathrm{~mL} / \mathrm{min}) .{ }^{68}$

The results of clinical trial ARTS-HF have been recently communicated in the European Society of Cardiology Congress. This trial compared increasing doses of finerenone with standard doses of eplerenone in patients who were susceptible to develop hyperkalemia (type II diabetics, or nondiabetics with GFR 30-60 mL/min). No significant differences were found in the main objective $(30 \%$ decrease of NT-proBNP levels), or in safety (same incidence of potassium $>5.6 \mathrm{mEq} / \mathrm{L}$ with both drugs, $4.3 \%) .{ }^{69}$ An improvement was observed in most of the secondary objectives (cardiovascular hospitalization, cardiovascular mortality, and mortality for any other reason; hazard ratio [HR] $0.56 ; P=0.0229)$, mainly in subgroups that received higher doses of finerenone (7.5 and $10 \mathrm{mg}$ ). For this reason, a new clinical trial has been designed (BAY 94-8862) ${ }^{70}$ to evaluate the morbimortality as main objective in a similar population (diabetics or patients with stage III CKD) treated with high doses of finerenone.

Another new drug with a lower risk of hyperkalemia is LCZ696, the first of the angiotensin and neprilysin inhibitors, a molecule that contains neprilysin inhibitor (sacubitril) and ARB valsartan. Neprilysin is an enzyme that degrades vasoactive peptides, among them natriuretic peptides. When the enzyme is inhibited, natriuretic peptides are accumulated, and an increase in beneficial effects is achieved. 
PARADIGM-HF is a double-blind, randomized study that included 8,442 patients with symptomatic HF and reduced ejection fraction, who were randomized to receive either LCZ696 $200 \mathrm{mg} / 12 \mathrm{~h}$ or enalapril $10 \mathrm{mg} / 12 \mathrm{~h}$, besides optimal therapy for systolic HF. This study was stopped prematurely after an average follow-up of 27 months, when a conclusive clinical benefit of LCZ696 versus enalapril was objectified. LCZ696 reduced the study primary end point (death for cardiovascular causes or HF hospitalization), which was observed in $21.8 \%$ of patients in the LCZ696 group opposite to $26.5 \%$ in the enalapril group (HR 0.80; 95\% confidence interval 0.73-0.87; $P<0.001)$. It was also separately related to a decrease in total mortality (17\% versus 19\%), HF hospitalizations $(12.8 \%$ versus $15.6 \%$ ), and clinical status improvement. LCZ696 frequent side effects were hypotension and mild angioedema. However, renal failure, hyperkalemia, and cough were reduced when compared to enalapril side effects (incidence of hyperkalemia $>6.0 \mathrm{mmol} / \mathrm{L}: 4.3$ in LCZ696 group versus 5.6 in enalapril group; $P=0.007$ ). Therefore, this new drug seems to be a future option in combination with standard treatment of $\mathrm{HF}$, or even an alternative in some patients with a high risk of hyperkalemia or renal failure. ${ }^{71}$

Likewise, there is a need for more secure and effective drugs which achieve a faster and sustained reduction of serum potassium levels in hyperkalemia patients.

Several studies of new oral drugs have been recently published. These drugs were based on polymers that are capable of chelating potassium into the colon, increasing its excretion, and proving a higher efficacy than resins used up to date, and thus avoiding their side effects without the need of modifying the patients' basal treatment (including ACE inhibitors, ARBs, and MRAs).

The US Food and Drug Administration approved on October 21, 2015 the first new treatment for hyperkalemia in the last 50 years. It is an oral suspension potassium binder named Patiromer, which fixes potassium in the colon and causes its elimination in blood, supported by three large clinical trials. The Pearl HF trial included patients who had discontinued an RAAS inhibitor or who showed a GFR $<60 \mathrm{~mL} / \mathrm{min}$, and who were treated with spironolactone, besides the standard therapy for HF. Patiromer had significantly lowered serum potassium levels compared with placebo, with a difference between groups of $-0.45 \mathrm{mEq} / \mathrm{L}$, a lower incidence of hyperkalemia ( $7.3 \%$ versus $24.5 \% ; P=0.015)$, and a higher proportion of patients on spironolactone $50 \mathrm{mg} /$ day (91\% versus $74 \% ; P=0.019){ }^{72}$

Furthermore, in the recent trial OPAL-HK, patients with potassium levels between 5.1 and $6.5 \mathrm{mEq} / \mathrm{L}$ who satisfactorily responded to Patiromer administration were selected. A satisfactory response to Patiromer was considered when patients showed potassium levels between 3.8 and $5.1 \mathrm{mEq} / \mathrm{L}$ after 4 weeks of treatment; $76 \%$ of the patients selected in the beginning reached this level. In the OPAL-HK trial, patients were randomized either to continue receiving Patiromer or to the placebo branch. Four weeks after randomization, hyperkalemia recurrence (potassium $>5.5 \mathrm{mEq} / \mathrm{L}$ ) was found in $>69 \%$ of patients taking placebo, and in $15 \%$ of patients taking Patiromer, with a low incidence of side effects (hypokalemia 3\%, mild-to-moderate constipation 11\%). ${ }^{73}$

Finally, the most recent study is called AMETHYST-DN, in which 306 outpatients with diabetes mellitus and CKD (estimated GFR between 15 and $60 \mathrm{~mL} / \mathrm{min}$ ) were stratified by baseline serum potassium levels and randomized to different starting doses of Patiromer. The primary efficacy end point was mean change in serum potassium level from baseline to week 4 , which was significantly reduced with every dose of Patiromer from 0.35 to $0.55 \mathrm{mEq} / \mathrm{L}$ in mild hyperkalemia and 0.87 to $0.97 \mathrm{mEq} / \mathrm{L}$ in moderate hyperkalemia. The most frequent adverse events were hypomagnesemia (7.2\%), constipation (6.3\%), and hypokalemia (5.6\%). ${ }^{74}$

Another one of these polymeric agents is sodium zirconium cyclosilicate (ZS-9). Packham et al carried a doubleblind, multicenter study (placebo versus ZS-9 at three different doses).${ }^{75}$ All patients included had potassium levels between 5 and $6.5 \mathrm{mmol} / \mathrm{L}$, and maintained basal treatment including diuretics (ACE inhibitors/ARBs and MRAs). The authors found a higher decrease of serum potassium level in patients treated with ZS-9 (4.6 mmol/L with ZS-9 versus $5 \mathrm{mmol} / \mathrm{L}$ in the placebo group; $P<0.01)$. The proportion of patients with mean potassium levels $<5.1 \mathrm{mmol} / \mathrm{L}$ were $80 \%$ with $5 \mathrm{~g}$, $90 \%$ with $10 \mathrm{~g}$, and $94 \%$ with $15 \mathrm{~g}$ of ZS-9, versus $46 \%$ with placebo ( $P<0.001$ for all comparisons versus placebo). These works provide a promising alternative to standard treatment of hyperkalemia because basal treatment with RAAS inhibitors can be maintained. ${ }^{76}$ However, more studies with larger samples and with patients with more severe hyperkalemia are needed in order to assess long-term effects.

\section{Conclusion}

In HF, hyperkalemia is a real problem due to patients' age, comorbidities, and renal failure on the one hand, and to neurohormonal mechanisms involved in HF and to the drugs used for its treatment on the other hand. These drugs have consistently proven the prognostic benefit for HF patients, so the objective should be to minimize the risk of acute renal failure and hyperkalemia in these patients (taking special care 
of associations with other drugs, such as NSAIDs), as well as to advance in research and in the use of new drugs like the new MRAs, and LCZ696. These have proven a benefit when added to standard HF therapy, reducing the risk of hyperkalemia. More studies are needed with new drugs in development for hyperkalemia treatment, like sodium zirconium cyclosilicate and Patiromer.

\section{Disclosure}

The authors report no conflicts of interest in this work.

\section{References}

1. Bielecka-Dabrowa A, Rysz J, Mikhailidis DP, Banach M. What is the risk of hyperkalemia in heart failure? Expert Opin Pharmacother. 2011; 12(15):2329-2338.

2. Shilpak MG. Pharmacotherapy for heart failure in patients with renal insufficiency. Ann Intern Med. 2003;138(11):917-924.

3. Rodrigues EJ, Eisenberg MJ, Pilote L. Effects of early and late administration of angiotensin-converting enzyme inhibitors on mortality after myocardial infarction. Am J Med. 2003;115(6):473-479.

4. Grigorian L, Varela A, Pedreira M, Gómez I, Virgós A, GonzálezJuanatey JR. La insuficiencia renal es un predictor independiente de la mortalidad en pacientes hospitalizados por insuficiencia cardiaca y se asocia con un peor perfil de riesgo cardiovascular [Renal failure is an independent predictor of mortality in hospitalized heart failure patients and is associated with a worse cardiovascular risk profile]. Rev Esp Cardiol. 2006;59(2):99-108. Spanish.

5. DesaiAS. Hyperkalemia in patients with heart failure: incidence, prevalence, and management. Curr Heart Fail Rep. 2009;6(4):272-280.

6. Torlén K, Kalantar-Zadeh K, Molnar M, Vashistha T, Mehrotra R. Serum potassium and cause-specific mortality in a large peritoneal dialysis cohort. Clin J Am Soc Nephrol. 2012;7(8):1272-1284.

7. Korgaonkar S, Tilea A, Gillespie B, et al. Serum potassium and outcomes in CKD: insights from the RRI-CKD cohort study. Clin J Am Soc Nephrol. 2010;5(5):762-769.

8. Xu Q, Xu L, Fan L, et al. Serum potassium levels and its variability in incident peritoneal dialysis patients: associations with mortality. PLoS One. 2014;9(1):e86750.

9. Kovesdy CP. Management of hyperkalemia in chronic kidney disease. Nat Rev Nephrol. 2014;10(11):653-662.

10. Palmer BF. Managing hyperkalemia caused by inhibitors of the renin-angiotensin-aldosterone system. $N$ Engl J Med. 2004;351(6): 585-592.

11. Amir O, Hassan Y, Sarriff A, Awaisu A, Abd Aziz N, Ismail O. Incidence of risk factors for developing hyperkalemia when using ACE inhibitors in cardiovascular diseases. Pharm World Sci. 2009;31(3): 387-393.

12. Desai AS, Swedberg K, McMurray JJ, et al. Incidence and predictors of hyperkalemia in patients with heart failure: an analysis of the CHARM Program. J Am Coll Cardiol. 2007;1950(20):1959-1966.

13. Phillips CO, Kashani A, Ko DK, Francis G, Krumholz HM. Adverse effects of combination angiotensin II receptor blockers plus angiotensinconverting enzyme inhibitors for left ventricular dysfunction: a quantitative review of data from randomized clinical trials. Arch Intern Med. 2007;167(18):1930-1936.

14. Stanton BA. Regulation of sodium and potassium transport by mineralocorticoids. Semin Nephrol. 1987;7(1):82-90.

15. Chakko SC, Frutchey J, Gheorghiade M. Life-threatening hyperkalemia in severe heart failure. Am Heart J. 1989;117(5):1083-1091.

16. Chan TY, Critchley JA. Life-threatening hyperkalemia in an elderly patient receiving captopril, furosemide and potassium supplements. Drug Saf. 1992;7(2):159-161.
17. Packer M,Lee WH. Provocation of hyper- and hypokalemic sudden death during treatment with and withdrawal of converting-enzyme inhibition in severe chronic congestive heart failure. Am J Cardiol. 1986;57(4):347-348.

18. Paice B, Gray JM, McBride D, et al. Hyperkalemia in patients in hospital. BMJ. 1983;286(6372):1189-1192.

19. Cody RJ, Ljungman S, Covit AB, et al. Regulation of glomerular filtration rate in chronic congestive heart failure patients. Kidney Int. 1988;34(3):361-367.

20. Obialo CI, Ofili EO, Mirza T. Hyperkalemia in congestive heart failure patients aged 63 to 85 years with subclinical renal disease. Am J Cardiol. 2002;90(6):663-665.

21. Lawson DH, O'Connor PC, Jick H. Drug attributed alterations in potassium handling in congestive cardiac failure. Eur J Clin Pharmacol. 1982;23(1):21-25.

22. Reardon LC, Macpherson DS. Hyperkalemia in outpatients using angiotensin-converting enzyme inhibitors. How much should we worry? Arch Intern Med. 1998;158(1):26-32.

23. Ramadan FH, Masoodi N, El-Solh AA. Clinical factors associated with hyperkalemia in patients with congestive heart failure. J Clin Pharm Ther. 2005;30(3):233-239.

24. Yusuf S, Teo KK, Pogue J, et al. Telmisartan, ramipril, or both in patients at high risk for vascular events. $N$ Engl J Med. 2008;358(15): 1547-1559.

25. Preston RA, Hirsh MJ, Oster MD, Oster HR. University of Miami Division of Clinical Pharmacology therapeutic rounds: drug induced hyperkalemia. Am J Ther. 1998;5(2):125-132.

26. Lown B, Black H, Moore FD. Digitalis, electrolytes and the surgical patient. Am J Cardiol. 1960;6:309-337.

27. Edes TE, Sunderrajan EJ. Heparin-induced hyperkalemia. Arch Intern Med. 1985;145(6):1070-1072.

28. Kamel KS, Ethier JH, Quaggin S, et al. Studies to determine the basis for hyperkalemia in recipients of a renal transplant who are treated with cyclosporine. J Am Soc Nephrol. 1992;2(8):1279-1284.

29. Muensterer OJ. Hyperkalaemic paralysis. Age Ageing. 2003;32(1): 114-115.

30. Finch CA, Sawyer CG, Flynn JM. Clinical syndrome of potassium intoxication. Am J Med. 1946;1:337-352.

31. Evers S, Engelien A, Karsch V, Hund M. Secondary hyperkalaemic paralysis. J Neurol Neurosurg Psychiatry. 1998;64(2):249-252.

32. Freeman SJ, Fale AD. Muscular paralysis and ventilatory failure caused by hyperkalemia. Br J Anaesth. 1993;70(2):226-227.

33. Parham WA, Mehdirad AA, Biermann KM, Fredman CS. Hyperkalemia revisited. Tex Heart Inst J. 2006;33(1):40-47.

34. Surawicz B, Chlebus H, Mazzoleni A. Hemodynamic and electrocardiographic effects of hyperpotassemia. Differences in response to slow and rapid increases in concentration of plasma K. Am Heart $J$. 1967;73(5):647-664.

35. Montague BT, Ouellette JR, Buller GK. Retrospective review of the frequency of ECG changes in hyperkalemia. Clin J Am Soc Nephrol. 2008;3(2):324-330

36. Acker CG, Johnson JP, Palevsky PM, Greenberg A. Hyperkalemia in hospitalized patients: causes, adequacy of treatment, and results of an attempt to improve physician compliance with published therapy guidelines. Arch Intern Med. 1998;158(8):917-924.

37. Szerlip HM, Weiss J, Singer I. Profound hyperkalemia without electrocardiographic manifestations. Am J Kidney Dis. 1986;7(6): $461-465$.

38. Aslam S, Friedman EA, Ifudu O. Electrocardiography is unreliable in detecting potentially lethal hyperkalemia in haemodialysis patients. Nephrol Dial Transplant. 2002;17(9):1639-1642.

39. Bashour T, Hsu I, Gorfinkel HJ, Wickramesekaran R, Rios JC. Atrioventricular and intraventricular conduction in hyperkalemia. $\mathrm{Am}$ J Cardiol. 1975;35(2):199-203.

40. Mattu A, Brady WJ, Robinson DA. Electrocardiographic manifestations of hyperkalemia. Am J Emerg Med. 2000;18(6):721-729.

41. Littmann L, Monroe MH, Taylor L 3rd, Brearley WD Jr. The hyperkalemic Brugada sign. J Electrocardiol. 2007;40(1):53-59. 
42. Weir R, Rolfe M. Potassium homeostasis and renin-angiotensinaldosterone system inhibitors. Clin J Am Soc Nephrol. 2010;5(3): 531-548.

43. Makani H, Bangalore S, Desouza K, Shah A, Messerli FH. Efficacy and safety of dual blockade of the renin-angiotensin system: meta-analysis of randomised trials. BMJ. 2013;346:f360.

44. Albert NM, Yancy CW, Liang L, et al. Use of aldosterone antagonists in heart failure. JAMA. 2009;302(15):1658-1665.

45. Rassi AN, Cavender MA, Fonarow GC, et al. Temporal trends and predictors in the use of aldosterone antagonists post-acute myocardial infarction. J Am Coll Cardiol. 2013;61(1):35-40.

46. Pitt B, Zannad F, Remme WJ, et al. The effect of spironolactone on morbidity and mortality in patients with severe heart failure. Randomized aldactone evaluation study investigators. NEngl J Med. 1999;341(10): 709-717.

47. Pitt B, Remme W, Zannad F, et al. Eplerenone, a selective aldosterone blocker, in patients with left ventricular dysfunction after myocardial infarction. N Engl J Med. 2003;348(14):1309-1321.

48. Zannad F, McMurray JJ, Krum H, et al. Eplerenone in patients with systolic heart failure and mild symptoms. N Engl J Med. 2011;364(1): 11-21.

49. Pitt B. Heart failure: the role for mineralocorticoid receptor antagonists. Swiss Med Wkly. 2014;144:w13959.

50. Juurlink DN, Mamdani MM, Lee DS, et al. Rates of hyperkalemia after publication of the Randomized Aldactone Evaluation Study. $N$ Engl J Med. 2004;351(6):543-551.

51. Zannad F, Gattis W, Rossignol P, et al. Mineralocorticoid receptor antagonists for heart failure with reduced ejection fraction: integrating evidence into clinical practice. Eur Heart J. 2012;33(22):2782-2795.

52. Khanna A, White W. The management of hyperkalemia in patients with cardiovascular disease. Am J Med. 2009;122(3):215-221.

53. Alper AB, Campbell RC, Anker SD, et al. A propensity-matched study of low serum potassium and mortality in older adults with chronic heart failure. Int J Cardiol. 2009;137(1):1-8.

54. Bowling CB, Pitt B, Ahmed MI, et al. Hypokalemia and outcomes in patients with chronic heart failure and chronic kidney disease: findings from propensity-matched studies. Circ Heart Fail. 2010;3(2): 253-260.

55. Castellino P, Bia MJ, DeFronzo RA. Adrenergic modulation of potassium metabolism in uremia. Kidney Int. 1990;37(2):793-798.

56. Reza MJ, Kovick RB, Shine KI, Pearce ML. Massive intravenous digoxin overdosage. N Engl J Med. 1974;291(15):777-778.

57. Adrogue HJ, Madias NE. Changes in plasma potassium concentration during acute acid-base disturbances. Am J Med. 1981;71(3):456-467.

58. Sica D, Hess M. Aldosterone receptor antagonism: interface with hyperkalemia in heart failure. Congest Heart Fail. 2004;10(5):259-264.

59. Green D, Green HD, New DI, Kalra PA. The clinical significance of hyperkalaemia-associated repolarization abnormalities in end-stage renal disease. Nephrol Dial Transplant. 2013;28(1):99-105.

60. Winkler AW, Hoff HE, Smith PK. Factors affecting the toxicity of potassium. Am J Physiol. 1939;127:430-435.
61. Allon M, Copkney C. Albuterol and insulin for treatment of hyperkalemia in hemodialysis patients. Kidney Int. 1990;38(5):869-872.

62. Salem MM, Rosa RM, Batlle DC. Extrarenal potassium tolerance in chronic renal failure. Am J Kidney Dis. 1991;18(4):421-440.

63. Pancu D, LaFlamme M, Evans E, Reed J. Levalbuterol is as effective as racemic albuterol in lowering serum potassium. J Emerg Med. 2003; 25(1):13-16.

64. Kamel SK, Wei C. Controversial issues in the treatment of hyperkalemia. Nephrol Dial Transplant. 2003;18(11):2215-2218.

65. Vasavada N, Saha C, Agarwal R. A double-blind randomized crossover trial of two loop diuretics in chronic kidney disease. Kidney Int. 2003;64(2):632-640.

66. Zehnder C, Gutzwiller JP, Huber A, Schindler C, Schneditz D. Low potassium and glucose free dialysis maintains urea but enhances potassium removal. Nephrol Dial Transplant. 2001;16(1):78-84.

67. Gruy-Kapral C, Emmett M, SantaAna CA, Porter JL, Fordtran JS, Fine KD. Effect of single dose resin-cathartic therapy on serum potassium concentration in patients with end-stage renal failure. J Am Soc Nephrol. 1998;9(10):1924-1930.

68. Pitt B, Kober L, Ponikowski P, et al. Safety and tolerability of the novel non-steroidal mineralocorticoid receptor antagonist Bay 94-8862 in patients with chronic heart failure and mild or moderate chronic kidney disease: a randomized, double-blind trial. Eur Heart J. 2013;34(31):2453-2463.

69. Pitt B, Anker SD, Böhm M, et al. Rationale and design of MinerAlocorticoid Receptor antagonist Tolerability Study-Heart Failure (ARTS-HF): a randomized study of finerenone vs eplerenone in patients who have worsening chronic heart failure with diabetes and/or chronic kidney disease. Eur J Heart Fail. 2015;17(2):224-232.

70. Bramlage P, Swift S, Thoenes M, Minguet J, Ferrero C, Schmieder RE. Non-steroidal mineralocorticoid receptor antagonism for the treatment of cardiovascular and renal disease. Eur J Heart Fail. 2015. [Epub ahead of print].

71. McMurray J, Packer M, Desai A, et al. Angiotensin-neprilysin inhibition versus enalapril in heart failure. N Engl J Med. 2014;371(11): 993-1004.

72. Pitt B, Anker SD, Bushinsky DA, Kitzman DW, Zannad F, Huang IZ. Evaluation of the efficacy and safety of rly5016, a polymeric potassium binder, in a double-blind, placebo-controlled study in patients with chronic heart failure (the PEARL-HF) trial. Eur Heart J. 2011;32(7): $820-828$.

73. Pitt B, Anker SD, Böhm M, et al. Patiromer in patients with kidney disease and hyperkalemia receiving RAAS inhibitors. $N$ Engl J Med. 2015;372(3):211-221.

74. Bakris G, Pitt B, Weir M, et al. Effect of patiromer on serum potassium level in patients with hyperkalemia and diabetic kidney disease. JAMA. 2015;314(2):151-161.

75. Packham DK, Rasmussen HS, Lavin PT, et al. Sodium zirconium cyclosilicate in hyperkalemia. N Engl J Med. 2015;372(3):222-231.

76. Wise J. Two drugs show promising results for treating hyperkalemia in US study. BMJ. 2015;17(350):h278.
Research Reports in Clinical Cardiology

\section{Publish your work in this journal}

Research Reports in Clinical Cardiology is an international, peerreviewed, open access journal publishing original research, reports, editorials, reviews and commentaries on all areas of cardiology in the clinic and laboratory. The manuscript management system is completely online and includes a very quick and fair peer-review system.

\section{Dovepress}

Visit http://www.dovepress.com/testimonials.php to read real quotes from published authors. 